\title{
PENGARUH ORIENTASI KEWIRAUSAHAAN TERHADAP KINERJA UMKM DI JABODETABEK DENGAN INDIVIDUALISME SEBAGAI VARIABEL MODERASI
}

\author{
Juli Yanto \\ Program Studi Magister Manajemen Universitas Tarumanagara \\ juliyanto.thang@gmail.com
}

Masuk : 06-06-2020, revisi : 26-06-2020 diterima untuk diterbitkan : 29-06-2020

\begin{abstract}
The purpose of this study is to examine the effects of Entrepreneurship Orientation conducted by SMEs on firm performance, and exploring new concepts regarding Executive's Individualism to moderate Entrepreneurial Orientation on SMEs performance. The sample was selected using a non-probability sampling method. The total sample chosen was 259 SMEs in the Greater Jakarta area. The method of analysis used was PLS-SEM. The results of this study indicate that 1) Entrepreneurial Orientation has a positive effect on the performance of SMEs companies in the Greater Jakarta area 2) Executive's Individualism strengthens the relationship between Entrepreneurship Orientation with SMEs Firm Performance in the Greater Jakarta area, specifically financial performance - profit.
\end{abstract}

Keywords: Entrepreneurial Orientation, Organizational Culture, Individualism, Firm Performance, SMEs

\begin{abstract}
Abstrak: Tujuan dari penelitian ini adalah untuk menguji pengaruh Orientasi Kewirausahaan yang dilakukan oleh UMKM terhadap kinerja perusahaan, dan mengeksplorasi konsep-konsep baru tentang Individualisme Eksekutif dalam memoderasi Orientasi Kewirausahaan terhadap kinerja UMKM. Sampel dipilih menggunakan metode sampling non-probabilitas. Total sampel yang dipilih adalah 259 UMKM di wilayah Jabodetabek. Metode analisis yang digunakan adalah PLS-SEM. Hasil penelitian ini menunjukkan bahwa 1) Orientasi Kewirausahaan memiliki efek positif pada kinerja UMKM di wilayah Jabodetabek 2) Eksekutif Individualisme memperkuat hubungan antara Orientasi Kewirausahaan dengan Kinerja UMKM di wilayah Jabodetabek, khususnya kinerja keuangan - profit.
\end{abstract}

Kata Kunci: Orientasi Kewirausahaan, Budaya Organisasi, Individualisme, Kinerja Perusahaan, UMKM

\section{PENDAHULUAN}

Usaha Mikro, Kecil, dan Menengah (UMKM) telah mampu membuktikan eksistensinya dalam perekonomian di Indonesia. Ketika badai krisis moneter melanda Indonesia di tahun 1998 UMKM relatif mampu bertahan dibandingkan perusahaan besar. Hal ini karena mayoritas usaha berskala kecil tidak terlalu tergantung pada modal besar atau pinjaman dari luar dalam mata uang asing. UMKM memiliki peranan penting dalam perekonomian di Indonesia. UMKM memiliki proporsi sebesar 99,99\% dari total keseluruhan pelaku usaha di Indonesia, menyumbang PDB sekitar 60\% (Sarwono, 2015). Beberapa peran penting UMKM dalam perekonomian Indonesia, yaitu: penyedia lapangan kerja yang terbesar; pemain penting dalam pengembangan kegiatan ekonomi lokal dan pemberdayaan masyarakat; pencipta pasar baru dan sumber inovasi; serta sumbangannya dalam menjaga neraca pembayaran melalui kegiatan ekspor. Meskipun demikian, masih terdapat beberapa hambatan internal maupun eksternal yang harus dihadapi pelaku UMKM.

Berdasarkan data dari Kementerian Koperasi dan Usaha Kecil dan Menengah Republik Indonesia yang diolah dari data Badan Pusat Statistik, peranan UMKM terhadap total Ekspor Non Migas masih kecil kontribusi nya bahkan mengalami penurunan dari tahun 2017 ke 2018 sebesar Rp.7.789 Milyar atau sebesar 2,58\%, sedangkan untuk Usaha Besar juga mengalami 
penurunan lebih kecil dari UMKM yaitu hanya sebesar 1,22\%. Jabodetabek yang merupakan salah satu pusat perekonomian di Indonesia diharapkan mampu meningkatkan kinerja perusahaannya. Berdasarkan hasil sensus Ekonomi yang dikeluarkan BPS tahun 2016 mengungkapkan bahwa UMKM di Jabodetabek khususnya DKI Jakarta memberikan kontribusi pendapatan nasional sebesar $6,55 \%$ dengan rasio pengeluaran terhadap pendapatan sebesar 0,7 (BPS, 2016). Hal ini menunjukkan bahwa DKI Jakarta memiliki kinerja yang lebih baik dibandingkan dengan provinsi lainnya. Mengingat pentingnya peranan UMKM dalam membantu perkembangan ekonomi di Indonesia, maka tentunya hal tersebut perlu untuk terus dijaga dan ditingkatkan. Oleh karena itu, perlu dilakukan penelitian mengenai kinerja UMKM di Indonesia, khususnya di Jabodetabek.

Tambunan (2008) mengungkapkan bahwa daya saing yang rendah dari UMKM menyebabkan kelompok ini mengalami kesulitan dalam meningkatkan kinerjanya. Banyak faktor yang dapat mempengaruhi kinerja suatu perusahaan, salah satu nya yaitu Orientasi Kewirausahaan. Beberapa penelitian terdahulu menunjukan hasil bahwa orientasi kewirausahaan dapat meningkatkan kinerja perusahaan (Anlesinya et al., 2015; Hutahayan, 2019; Kim \& Kim, 2016; Magaji et al., 2017; Soares \& Perin, 2019). Faktor internal dan eksternal perusahaan dapat memoderasi hubungan antara orientasi kewirausahaan dan kinerja (Lumpkin \& Dess, 1996). Sebagian besar penelitian sebelumnya telah mengabaikan efek karakteristik dari kepribadian, yaitu individualisme eksekutif pada hubungan antara orientasi kewirausahaan dengan kinerja (Yucel, 2011). Oleh karena itu, penelitian ini berkontribusi pada literatur kewirausahaan dengan meneliti efek individualisme pada hubungan antara kewirausahaan dan kinerja perusahaan

\section{TELAAH KEPUSTAKAAN}

\section{Resource Based View (RBV) \& Consumer Culture Theory (CCT)}

Penelitian ini dibangun berdasarkan kolaborasi dari dua konsep teori, yaitu ResourceBased View (RBV) dan Customer Culture Theory (CCT). Teori RBV dikembangkan oleh (Barney, 1991) dan teori CCT dikembangkan oleh (Arnould \& Thompson, 2005). Kinerja adalah fungsi dari kumpulan sumber daya unik dan kemampuan yang dimiliki dan dikendalikan oleh perusahaan (Barney, 1991). Kerangka kerja konseptual RBV Theory memungkinkan untuk mengidentifikasi sumber daya perusahaan yang berpotensi menjadi pendorong kinerja perusahaan dengan menghubungkan sumber daya, kemampuan, dan tindakan tegas dengan pencapaian keunggulan kompetitif berkelanjutan yang menghasilkan keuntungan yang lebih tinggi daripada pesaing. Arnould \& Thompson (2005) menyatakan bahwa CCT Theory adalah untuk memenuhi beberapa panggilan atas riset konsumen dari pemikiran para pemimpin tentang konsumsi dan perilaku pasar. $C C T$ berusaha secara sistematis menghubungkan makna tingkat individu (atau idiografis) dengan berbagai tingkat proses dan struktur budaya dan kemudian menempatkan hubungan-hubungan ini dalam konteks sejarah dan pasar.

\section{Orientasi Kewirausahaan}

Lumpkin \& Dess (1996) berpendapat bahwa Orientasi Kewirausahaan mengacu pada proses, praktik, dan kegiatan pengambilan keputusan yang mengarah pada entri baru. Dimensi kunci yang menjadi karakteristik Orientasi Kewirausahaan termasuk kecenderungan untuk bertindak secara mandiri, kemauan untuk berinovasi dan mengambil risiko, serta kecenderungan untuk menjadi agresif terhadap pesaing dan relatif proaktif terhadap peluang pasar. Miller (1983) menyatakan bahwa Orientasi Kewirausahaan adalah kombinasi dari pengambilan risiko, inovasi dan proaktif. Lumpkin \& Dess (1996) mengidentifikasi dua dimensi tambahan, "otonomi" dan "agresivitas kompetitif", untuk melengkapi tiga dimensi asli yang diusulkan oleh (Miller, 1983).

\section{Eksekutif Individualisme}

Hofstede (2011) menyatakan bahwa enam dimensi dari budaya nasional yaitu : Power Distance, Uncertainty Avoidance, Individualism versus Collectivism, Masculinity versus 
Femininity, Long Term versus Short Term Orientation, Indulgence versus Restraint. Gil et al. (2019) menyatakan bahwa individualisme dapat digambarkan sebagai pola sosial yang melibatkan individu-individu yang memiliki ikatan longgar yang memandang diri mereka sebagai kelompok yang independen; kebutuhan, preferensi, hak, dan kontrak mereka memotivasi orang-orang ini.

\section{Kinerja Perusahaan}

Kinerja perusahaan adalah sebuah hasil dari proses bisnis perusahaan yang menunjukkan nilai keberhasilan dari sebuah usaha yang bisa diukur dengan informasi keuangan maupun non keuangan. Kinerja keuangan dapat dinilai dari ukuran-ukuran angka dalam laporan keuangan, sedangkan kinerja non keuangan dapat berupa kepuasan pelanggan serta kualitas produk. Untuk mencapai kinerja relatif yang unggul, organisasi harus mencapai target yang diharapkan dengan efisiensi dan efektivitas yang lebih besar untuk menyamai para pesaingnya (Wu \& Zhao, 2009).

\section{Kaitan Antar Variabel}

\section{Orientasi Kewirausahaan terhadap Kinerja Perusahaan}

Soares \& Perin (2019) menyatakan bahwa orientasi kewirausahaan memainkan peran penting dalam meningkatkan kinerja perusahaan. Orientasi kewirausahaan memotivasi perusahaan untuk secara agresif meluncurkan inovasi produk, mengeksplorasi peluang dan mendukung kegiatan pengembangan produk baru. Orientasi kewirausahaan berkontribusi pada kesuksesan produk baru dengan memungkinkan perusahaan untuk mengidentifikasi dan secara proaktif memanfaatkan peluang bisnis baru. Omisakin et al. (2016) menyatakan bahwa Inovatif cenderung mendukung pembaruan dalam menciptakan produk dan layanan baru. Perusahaan yang inovatif umumnya memiliki basis keterampilan dan pengetahuan yang lebih luas yang memberi mereka keunggulan terhadap pesaing mereka. Perusahaan yang berorientasi pada inovasi akan mampu memunculkan ide baru yang bertujuan untuk mengembangkan produk atau layanan sehingga dapat meningkatkan kinerja perusahaan. Hasil penelitian mengungkapkan adanya hubungan positif antara Orientasi Kewirausahaan dan kinerja perusahaan.

\section{Moderasi Eksekutif Individualisme terhadap hubungan Orientasi Kewirausahaan dan Kinerja Perusahaan}

Yucel (2011) menyatakan bahwa ambisi, otonomi, kesediaan untuk mengambil risiko dan agresivitas kompetitif yang diperoleh melalui individualisme akan membantu para eksekutif dalam mengantisipasi inovasi masa depan dan memilih strategi yang tepat dalam kondisi ketidakpastian. Perusahaan-perusahaan yang berorientasi wirausaha diposisikan untuk mengeksploitasi individualisme dari para eksekutif untuk menilai dan memanfaatkan peluang dengan lebih baik melalui keputusan strategis yang kreatif.

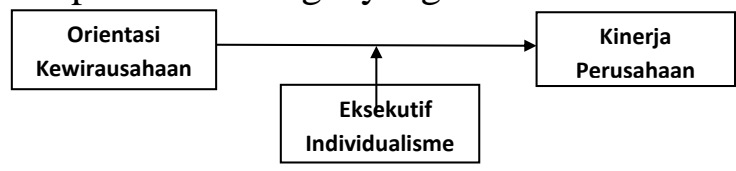

Gambar 1

\section{Model Penelitian}

Berdasarkan paparan di atas, maka hipotesis penelitian adalah sebagai berikut:

H1 : Orientasi Kewirausahaan berpengaruh positif terhadap Kinerja Perusahaan UMKM di wilayah Jabodetabek.

H2 : Eksekutif Individualisme memperkuat hubungan antara Orientasi Kewirausahaan dengan Kinerja Perusahaan UMKM di wilayah Jabodetabek.

\section{METODOLOGI PENELITIAN}

Desain dari penelitian ini adalah penelitan deskriptif dan verifikatif. Deskriptif adalah karateristik responden yang meliputi jenis usaha, lama usaha, jumlah tenaga kerja, struktur modal, serta struktur manajemen. Verifikatif adalah ingin mengetahui bagaimana hubungan 
dan sifat hubungan antar variabel satu dengan yang lainnya. Sampel dipilih dengan menggunakan metode non-probability sampling, dimana responden yang dipilih yaitu pelaku UMKM yang berdomisili di wilayah Jabodetabek. Pengumpulan data dilakukan dengan membagikan kuesioner secara online dengan menggunakan google-form yang disebarkan melalui media online yaitu whatsapp messenger, line, serta telegram. Sebanyak 259 sampel pelaku UMKM didapatkan dalam penelitian ini. Metode analisis data dalam penelitian ini menggunakan program SmartPLS 3.

Pengukuran objek penelitian diukur menggunakan indikator dengan skala rasio dan skala ordinal 1-10. Skala ini digunakan karena kebiasaan kita menilai sesuatu dari nilai yang paling rendah yaitu satu dan nilai yang paling tinggi yaitu sepuluh. Tabel 1 menunjukan pengukuran masing-masing variabel dan sumbernya, instrumen tersebut telah dilakukan analisis validitas dengan hasil analisis convergent validity dan discriminant validity. Sementara untuk analisis reliabilitas didasarkan pada nilai cronbach's alpha dan composite reliability yang masingmasing hasilnya menunjukan nilai lebih dari 0,7 sehingga semua indikator dalam penelitian adalah reliabel (Hair et al., 2014).

Berdasarkan data yang telah dikumpulkan, diketahui bahwa bidang usaha mayoritas responden yaitu usaha perdagangan sebanyak 123 orang (47\%), lama usaha mayoritas dibawah 3 tahun sebanyak 63 orang, sebanyak 67 orang (24\%) memiliki 2 tenaga kerja pada saat mendirikan usaha, sebanyak 204 responden (79\%) tidak melibatkan modal pihak lain pada saat mendirikan usaha, sebanyak 132 responden (51\%) menjawab tidak melibatkan keluarga inti dalam struktur manajemen, dan sebanyak 181 responden (70\%) menjawab tidak pernah mendapatkan pinjaman bank.

\section{Tabel 1}

Variabel data Pengukuran

\begin{tabular}{|l|l|l|}
\hline Variabel & Jumlah Item & Sumber \\
\hline $\begin{array}{l}\text { Variabel Independen } \\
\text { Orientasi Kewirausahaan }\end{array}$ & 28 & $\begin{array}{l}\text { (Dess \& Lumpkin, 2005) } \\
\text { (Lee \& Lim, 2009) }\end{array}$ \\
\hline $\begin{array}{l}\text { Variabel Moderasi } \\
\text { Eksekutif Individualisme }\end{array}$ & 9 & (Cozma, 2011) \\
\hline $\begin{array}{l}\text { Variabel Dependen } \\
\text { Kinerja Perusahaan }\end{array}$ & 7 & $\begin{array}{l}\text { (Jalali et al., 2013) } \\
\text { (Aladejebi et al., 2018) }\end{array}$ \\
\hline
\end{tabular}

\section{Hasil Uji Statistik}

Hasil pengujian koefisien determinasi R2 dari penelitian ini menunjukan nilai R square untuk variabel Kinerja - Non Keuangan adalah sebesar 0,486, variabel Kinerja - Penjualan adalah sebesar 0,055 dan variabel Kinerja - Profit adalah sebesar 0,098. Nilai R Square 0,486 untuk variabel Kinerja - Non Keuangan berarti bahwa sebesar 48,6\% dari variabel Kinerja Non Keuangan dijelaskan oleh variabel-variabel yang terdapat dalam penelitian ini dan sisanya yaitu sebesar 51,4\% (100\% - 48,6\%) dijelaskan oleh variabel-variabel diluar penelitian. Berdasarkan pendapat yang dikemukakan oleh (Hair et al., 2014).

Tabel 2

Hasil Pengujian Hipotesis

\begin{tabular}{l|l|l}
\hline Variable & Coefficient & T-statistic \\
\hline EI -> KP - Non keuangan & $-0,157$ & $2,545^{*}$ \\
\hline EI -> KP - Penjualan & 0,085 & 1,634 \\
\hline EI -> KP - Profit & 0,126 & 1,878 \\
\hline Moderating Effect 1 -> KP - Penjualan & 0,048 & 1,823 \\
\hline Moderating Effect 2 -> KP - Profit & 0,084 & $2,525^{*}$ \\
\hline Moderating Effect 3 - KP - Non keuangan & 0,003 & 0,086 \\
\hline OK -> KP - Non keuangan & 0,766 & $11,915^{*}$ \\
\hline OK - KP - Penjualan & 0,182 & $3,958^{*}$ \\
\hline OK -> KP - Profit & 0,227 & $3,635^{*}$ \\
\hline 0,05 & &
\end{tabular}

Berdasarkan Tabel 2. di atas dapat ditarik kesimpulan bahwa Orientasi Kewirausahaan terhadap Kinerja - Non keuangan, Kinerja - Penjualan dan Kinerja - Profit memiliki kontribusi yang positif masing-masing sebesar 0,766, 0,182 dan 0,227. Eksekutif Individualisme tidak memiliki kontribusi untuk berpengaruh terhadap Kinerja - Penjualan dan Kinerja - Profit, 
tetapi memiliki kontribusi yang negatif terhadap Kinerja - Non Keuangan sebesar 0,157. Variable Eksekutif Individualisme memoderasi hubungan positif terhadap Orientasi Kewirausahaan dengan Kinerja - Profit sebesar 0,084. Hal ini dibuktikan dengan nilai $t$ statistics lebih besar dari cut off value sebesar 1,96.

\section{Diskusi}

Orientasi Kewirausahaan terbukti berpengaruh secara positif terhadap seluruh kinerja perusahaan, baik keuangan maupun non-keuangan (penjualan \& profit). Dari hasil ini, maka seorang wirausahawan diharapkan dapat mengembangkan Orientasi Kewirausahaan yang dimiliki agar dapat meningkatkan kinerja perusahaan. Dimensi kunci yang menjadi karakteristik Orientasi Kewirausahaan termasuk kecenderungan untuk bertindak secara mandiri, kemauan untuk berinovasi dan mengambil risiko, dan kecenderungan untuk menjadi agresif terhadap pesaing dan relatif proaktif terhadap peluang pasar dapat menjadikan perusahaan tersebut bisa merebut pangsa pasar sehingga dapat meningkatkan Kinerja Perusahaan. Dalam penelitian ini juga terlihat bahwa salah satu indikator dari dimensi proaktif mempunyai peran yang sangat signifikan dalam mempengaruhi kinerja, sehingga diharapkan seorang wirausaha dapat terus proaktif dalam memantau tren dan mengidentifikasi kebutuhan pelanggan dimasa depan serta terus memperkenalkan produk dan teknologi baru sehingga lebih unggul dari pesaing dan dapat meningkatkan kinerja perusahaan. Hasil penelitian ini sesuai dengan penelitian terdahulu yang dilakukan oleh (Aladejebi et al., 2018; Cho \& Lee, 2018; Gautam, 2016; Herath \& Karunaratne, 2017; Herlinawati et al., 2019; Matthias et al., 2016) yang menyatakan bahwa orientasi kewirausahaan berpengaruh positif terhadap kinerja perusahaan.

Eksekutif Individualisme secara langsung berpengaruh terhadap Kinerja Non-Keuangan, namun tidak berpengaruh terhadap Kinerja Penjualan maupun Kinerja Profit. Di satu sisi Eksekutif Individualisme mampu memperkuat hubungan antara Orientasi Kewirausahaan dengan Kinerja Perusahaan khususnya Profit, namun tidak memoderasi hubungan antara Orientasi Kewirausahaan terhadap Kinerja Penjualan dan Kinerja - Non Keuangan. Sehingga dapat disimpulkan bahwa pengaruh moderasi Eksekutif Individualisme terhadap Orientasi Kewirausahaan dan variabel dependen Kinerja - Profit adalah pure moderasi. Ini menunjukkan bahwa ambisi, otonomi, kesediaan untuk mengambil risiko dan agresivitas kompetitif yang diperoleh melalui individualisme akan membantu para eksekutif dalam mengantisipasi inovasi masa depan dan dalam memilih strategi yang tepat dalam mengatasi kondisi ketidakpastian. Eksekutif terlibat langsung dalam perumusan strategi dan karakteristik mereka berdampak langsung pada kinerja perusahaan. Hal tersebut sesuai dengan penelitian terdahulu yang dilakukan oleh (Yucel, 2011) dan (Gil et al., 2019) yang menunjukkan bahwa orientasi kewirausahaan secara positif berhubungan dengan kinerja perusahaan dan eksekutif individualisme memainkan peran moderasi dalam hubungan ini.

\section{KESIMPULAN DAN SARAN}

Wirausahawan diharapkan dapat mengembangkan Orientasi Kewirausahaan yang dimiliki agar dapat meningkatkan Kinerja perusahaan. Perusahaan-perusahaan yang berorientasi wirausaha diharapkan juga agar dapat mengeksploitasi eksekutif individualisme untuk menilai dan memanfaatkan peluang dengan lebih baik melalui keputusan strategis yang kreatif. Karakteristik eksekutif tersebut memiliki dampak yang lebih besar pada kinerja perusahaan karena eksekutif puncak terlibat dalam perumusan strategi dan karakteristik mereka secara langsung berdampak pada kinerja perusahaan.

Bagi penelitian selanjutnya, dihimbau untuk menggunakan variabel lain, seperti kolektivisme dan karakterisik budaya organisasi lainnya dan juga memperluas cakupan penelitian. 


\section{DAFTAR RUJUKAN / PUSTAKA}

Aladejebi, O. A., Great, T., \& Clinic, B. (2018). Predictors of firm performance among selected SMEs in Lagos , Nigeria Predictors of firm performance among selected SMEs in Lagos, Nigeria. International Journal of Applied Research, 4(June), 8-17.

Anlesinya, A., Eshun, P., \& Bonuedi, A. A. (2015). Entrepreneurial Orientation Dimensions and Profitability Nexus: Evidence From Micro Enterprises in the Retail Sector in. International Journal of Small Business and Entrepreneurship Research, 3(7), 79-87.

Arnould, E. J., \& Thompson, C. J. (2005). Consumer Culture Theory (CCT): Twenty Years of Research. The University of Chicago Press and Journal of Consumer Research, 4(1), 44. https://doi.org/10.1016/s0098-7913(78)80071-9

Barney, J. (1991). Firm Resources and Sustained Competitive Advantage. Journal of Management, 17(1), 99-120.

BPS. (2016). Analisis Hasil SE2016 Lanjutan Potensi Peningkatan Kinerja Usaha Miko Kecil.

Cho, Y. H., \& Lee, J.-H. (2018). Entrepreneurial orientation, entrepreneurial education and performance. Asia Pacific Journal of Innovation and Entrepreneurship, 12(2), 124-134. https://doi.org/10.1108/apjie-05-2018-0028

Cozma, I. (2011). How are individualism and collectivism measured? Romanian Journal of Applied Psychology, 13(1), 11-17.

Dess, G. G., \& Lumpkin, G. T. (2005). The Role of Entrepreneurial Orientation in Stimulating Effective Corporate Entrepreneurship. Academy of Management Executive, 19(1), 4546. https://doi.org/10.1177/002248718203300610

Gautam, P. R. (2016). Handicraft Industry : a Study of Nepalese Handicraft. International Journal of Small Business and Entrepreneurship Research, 4(2), 48-63.

Gil, A., Brouthers, L. E., \& Keig, D. L. (2019). Top management team diversity, individualism-collectivism, and MNE performance. International Journal of Cross Cultural Management, 19(3), 273-290. https://doi.org/10.1177/1470595819870819

Hair, J. F., Sarstedt, M., Hopkins, L., \& Kuppelwieser, V. G. (2014). Partial least squares structural equation modeling (PLS-SEM): An emerging tool in business research. European Business Review, 26(2), 106-121. https://doi.org/10.1108/EBR-10-2013-0128

Herath, H. M. T. S., \& Karunaratne, H. D. (2017). Entrepreneurial Orientation of Information and Communication Technology Services Exports in Sri Lanka. Journal of Business and Economics, 8(7), 573-583. https://doi.org/10.15341/jbe(2155-7950)/07.08.2017/006

Herlinawati, E., Suryana, Ahman, E., \& Machmud, A. (2019). Pengaruh Orientasi Wirausaha terhadap Kinerja Bisnis UKM di Indonesia. Jurnal Pendidikan Kewirausahaan, 22(5), $1-9$.

Hofstede, G. (2011). Dimensionalizing Cultures: The Hofstede Model in Context. Online Readings in Psychology and Culture, 2(1), 1-26. https://doi.org/10.9707/23070919.1014

Hutahayan, B. (2019). Factors affecting the performance of Indonesian special food SMEs in entrepreneurial orientation in East Java. Asia Pacific Journal of Innovation and Entrepreneurship, 13(2), 231-246. https://doi.org/10.1108/apjie-09-2018-0053

Jalali, A., Jaafar, M., \& Thurasamy, R. (2013). Influence of entrepreneurial orientation on the financial performance: evidence from SMEs in Iran. Middle East J. of Management, 1(2), 168. https://doi.org/10.1504/mejm.2013.057263

Kim, H.-J., \& Kim, B.-K. (2016). An entrepreneurial paradox: the moderating effect of the external environment. Asian Journal of Technology Innovation, 24(2), 222-233. https://doi.org/10.1080/19761597.2016.1207414

Lee, S. M., \& Lim, S. (2009). Entrepreneurial orientation and the performance of service business. Service Business, 3(1), 1-13. https://doi.org/10.1007/s11628-008-0051-5

Lumpkin, G. T., \& Dess, G. G. (1996). Clarifying The Entrepreneural Orientation Construct and Linking it to Performance. Academy of Management Review, 21(1), 135-172. 
https://doi.org/10.2307/258632

Magaji, M. S., Baba, R., \& Entebang, H. (2017). Entrepreneurial Orientation and Financial Performance of Nigerian SMES: The Moderating Role of Environment. A Review of Literature. Journal of Management and Training for Industries, 4(1), 25-41. https://doi.org/10.12792/jmti.4.1.25

Matthias, E. E., Agwu, A.-N. E., \& Onyeizugbe, C. U. (2016). Entrepreneurial Orientation and Performance of Small and Medium Scale Enterprises in Ebonyi State. International Journal in Management and Social Science, 04(05), 300-312.

Miller, D. (1983). The Correlates of Entrepreneurship in Three Types of Firms. Management Science, 29(7), 770-791. https://doi.org/10.1287/mnsc.29.7.770

Omisakin, O. M., Nakhid, C., Littrell, R., \& Verbitsky, J. (2016). Entrepreneurial Orientation among Migrants and Small and Medium Enterprises. Journal of Business Administration Research, 5(1), 7-22. https://doi.org/10.5430/jbar.v5n1p7

Sarwono, H. A. (2015). Profil Bisnis Usaha Mikro, Kecil Dan Menengah (Umkm). Bank Indonesia Dan LPPI, 1-135.

Soares, M. do C., \& Perin, M. G. (2019). Entrepreneurial orientation and firm performance: an updated meta-analysis. RAUSP Management Journal, 55(2), 143-159. https://doi.org/10.1108/RAUSP-01-2019-0014

Tambunan, T. (2008). SME development, economic growth, and government intervention in a developing country: The Indonesian story. Journal of International Entrepreneurship, 6(4), 147-167. https://doi.org/10.1007/s10843-008-0025-7

Wu, D., \& Zhao, F. (2009). Measuring Performance in Small and Medium Enterprises in the Information \& Communication Technology Industries (Issue February).

Yucel, I. (2011). Entrepreneurial orientation, executives individualism and Firm Performance: The moderating role of executives individualism. Far East Journal of Psychology and Business, 5(3), 63-78. http://www.fareastjournals.com/files/FEJPBV5N3P3.pdf 